\title{
Pregnanolone Sulfate Promotes Desensitization of Activated NMDA Receptors
}

\author{
Cassandra L. Kussius, Navjot Kaur, and Gabriela K. Popescu \\ Department of Biochemistry, School of Medicine and Biomedical Sciences, University at Buffalo, Buffalo, New York 14214
}

Neurosteroids are potent neuromodulators which act in part by binding to and modifying the activity of neurotransmitter-gated channels. Pregnanolone sulfate (PAS) is an endogenous neurosteroid that inhibits NMDA receptors and is neuroprotective in vivo. To delineate the mechanism of NMDA receptor inhibition by pregnanolone sulfate we used kinetic analyses of equilibrium single-channel currents recorded from individual GluN1/GluN2A receptors. Results show that PAS (0.1 mM) reduces single-channel open probability by $50 \%$ solely by increasing $\sim 5$-fold the mean time spent by receptors in closed conformations. From these data we derive a kinetic scheme that summarizes the effects of PAS on single channel kinetics, accounts for the PAS effects on macroscopic responses and leads us to propose that PAS inhibits NMDA receptor activity by shifting active receptors into desensitized conformations. These findings highlight the neurosteroid inhibitory site on NMDA receptors as a valuable therapeutic target against excitotoxic pathologies including acute and chronic neurodegeneration.

\section{Introduction}

NMDA receptors are glutamate-activated channels required for normal brain function and development but are also major contributors to excitotoxic neurodegeneration (Waxman and Lynch, 2005; Paoletti and Neyton, 2007). They assemble as tetramers of two GluN1 and two GluN2 subunits and in addition to binding the coagonists glutamate and glycine, they also recognize a multiplicity of endogenous and pharmacologic modulators, including the physiological neurosteroid pregnanolone sulfate ( $\mathrm{Wu}$ et al., 1991).

Pregnanolone sulfate (PAS) is an endogenous metabolite of progesterone that inhibits NMDA receptors in vitro and its more soluble synthetic derivative pregnanolone hemisuccinate confers in vivo neuroprotection in animal models of stroke (Park-Chung et al., 1994; Weaver et al., 1997; Malayev et al., 2002; Lapchak, 2006). PAS inhibition of NMDA receptors is voltageindependent and noncompetitive with other known modulators (Gibbs et al., 2006). Thus, the PAS-modulatory site on the NMDA receptor may offer a valuable target to pharmacologically attenuate NMDA receptor-mediated fluxes for therapeutic gain.

It was recently proposed that PAS is a use-dependent allosteric inhibitor of GluN1/GluN2B receptors (Petrovic et al., 2005). To identify the kinetic mechanism by which this effect occurs we examined the activity of single NMDA receptors in the presence of PAS. Single-channel currents recorded from NMDA receptors display complex patterns of stochastic transitions among multiple receptor states, some of which are nonconducting (closed, C) whereas others are highly permeable to cations (open, O). Kinetic

\footnotetext{
Received Jan. 18, 2009; revised March 25, 2009; accepted April 9, 2009.

This work was funded in part by a Scientist Development Grant from the American Heart Association (0535268N to G.K.P.). We thank Barbara Bistram and Jason Myers for technical assistance.

Correspondence should be addressed to Gabriela K. Popescu at the above address. E-mail: popescu@buffalo.edu. DOI:10.1523/JNEUROSCI.0281-09.2009

Copyright $\odot 2009$ Society for Neuroscience $\quad$ 0270-6474/09/296819-09\$15.00/0
}

analyses of these records have identified multiple distinct closed and open kinetic components (Howe et al., 1988; Gibb and Colquhoun, 1991, 1992; Howe et al., 1991; Stern et al., 1994). Further, recent work has shown that within clusters of activity NMDA receptors visit at least 3 closed and 2 open states (Banke and Traynelis, 2003; Popescu and Auerbach, 2003; Auerbach and Zhou, 2005; Schorge et al., 2005); and clusters are terminated by receptor sojourns into either of two long closed states believed to represent microscopic desensitization (Banke and Traynelis, 2003; Erreger et al., 2005; Dravid et al., 2008; Zhang et al., 2008).

Aside from multistate gating, the complexity of singlechannel NMDA receptor records is amplified by modal behavior. Modal gating refers to low-probability transitions which result in minutes-long periods with distinct and characteristic mean open durations (MOT) (Popescu and Auerbach, 2003). So far, for GluN1/GluN2A receptors, three gating modes have been characterized. Because within each mode, channels visit only 2 types of openings, even when originating from only one receptor, open distributions can have at least two (unimodal record) and up to four open components (trimodal record).

Using detailed kinetic analyses and modeling of equilibrium single-channel currents recorded from one-channel patches, we found that PAS decreased the open probability of GluN1/ GluN2A channels by inducing activated receptors to accumulate into desensitized conformations. This mechanism is consistent with previously reported effects of PAS on macroscopic NMDA receptor responses and provides further rationale for the exploration of neurosteroids as potential neuroprotective agents.

\section{Materials and Methods}

Chemicals and reagents

All reagents used for electrophysiology were reagent grade from Sigma. Pregnanolone sulfate ( $3 \alpha$-hydroxy- $5 \beta$-pregnan-20-one sulfate; $3 \alpha 5 \beta S$; PAS) was from Steraloids. 


\section{Cells and transfections}

HEK cells (ATCC CRL-1573) were a gift from Dr. A. Auerbach (University at Buffalo, Buffalo, NY). They were maintained in DMEM supplemented with $10 \%$ fetal bovine serum and $1 \%$ pen-strep mixture, at $37^{\circ} \mathrm{C}$, in a $5 \% \mathrm{CO}_{2}$ atmosphere. They were passed when reaching $80-90 \%$ confluence and passages 22-40 were used for transfections. Tissue culture reagents were purchased from Invitrogen. Plasmids encoding rat NR1-1a (GluN1, U08261) and rat NR2A (GluN2A, M91561) were gifts from Drs. R. J. Wenthold (National Institutes of Health, Bethesda, MD) and A. Auerbach, respectively. We subcloned open reading frames into pcDNA3 $(+)$ under the control of the CMV promoter. Complete sequence of each insert was confirmed periodically by sequencing.

Calcium precipitate-mediated transfections were done by incubating the cells for $2 \mathrm{~h}$ with mixtures consisting of (in mM): $140 \mathrm{NaCl}, 5 \mathrm{KCl}, 0.75$ $\mathrm{Na}_{2} \mathrm{HPO}_{4}, 6$ sucrose, $125 \mathrm{CaCl}_{2}, 25 \mathrm{HEPES} / \mathrm{NaOH}, \mathrm{pH} 7.05$, and $1 \mu \mathrm{g}$ of cDNA (GluN1:GluN2A:GFP = 1:1:1) per $35 \mathrm{~mm}$ dish containing cells at $\sim 50 \%$ density. After removing the precipitate, the cells were grown $24-48 \mathrm{~h}$ in growth medium supplemented with $2 \mathrm{mM} \mathrm{Mg}^{2+}$ to prevent NMDA receptor-mediated cell death.

Primary neuronal cultures were prepared from Sprague Dawley rat embryos with minor modifications from previously described methods (Misonou and Trimmer, 2005). Briefly, the frontal area of the cerebral cortex was collected from E18 rat embryos, and cells were dissociated using trypsin and gentle trituration through a Pasteur pipette. After removing tissue debris by filtration, isolated cells were plated in $35 \mathrm{~mm}$ dishes coated with poly-L-lysine at a density of $1 \times 10^{6} \mathrm{cells} / \mathrm{ml}$, in MEM with $10 \%$ fetal bovine serum, and $10 \%$ horse serum. Within $24 \mathrm{~h}$, the medium was changed to Neurobasal medium with B27 supplement. After $5 \mathrm{~d}$ in culture, AraC was added to inhibit cell division. Medium was changed every $5 \mathrm{~d}$ and cultures were assayed $\sim 2$ weeks later.

Before each experiment, cells were washed, covered with PBS and placed on the stage of an inverted microscope. Individual cells were selected visually, based on fluorescence intensity (transfected HEK cells) or morphology (pyramidal cortical neurons) and were patched while still attached to the dish.

\section{Electrophysiology}

Macroscopic currents were recorded with the whole-cell patch-clamp technique (Hamill et al., 1981). Glass electrodes were filled with (intracellular) solutions containing (in mM) $135 \mathrm{CsF}, 33 \mathrm{CsOH}, 2 \mathrm{MgCl}_{2}, 1$ $\mathrm{CaCl}_{2}, 10 \mathrm{HEPES}$, and 11 EGTA, adjusted to $\mathrm{pH} 7.4$ (CsOH). After reaching the whole-cell configuration, the voltage was clamped at -70 $\mathrm{mV}$ and cells were superfused with (extracellular) solutions using a lightly pressurized perfusion system that could exchange solutions within $0.3-0.5 \mathrm{~s}$ (BPS-8, ALA Scientific Instruments). Extracellular solutions contained (in mM) $150 \mathrm{NaCl}, 2.5 \mathrm{KCl}, 0.5 \mathrm{CaCl}_{2}, 0.1$ glycine, 0.01 mM EDTA and 10 HEPBS buffer, adjusted to $\mathrm{pH} 8(\mathrm{NaOH})$. Glutamate $(1 \mathrm{~mm})$ or glutamate and PAS were added as indicated. When recording from neurons, bicuculline $(5 \mu \mathrm{M})$ and CNQX $(10 \mu \mathrm{M})$ were added to these extracellular solution. Macroscopic currents were amplified and low-pass filtered at $2 \mathrm{kHz}$ (Axopatch 200B; 4-pole Bessel), sampled at 5 $\mathrm{kHz}$ (Digidata, 1322A), and written into digital files with pClamp 8 acquisition software (Molecular Devices).

Dose-response curve (see Fig. 1) was obtained by fitting the logistic equation to the means calculated from PAS-current levels normalized to the steady-state current level immediately prior drug-application.

Steady-state single-channel currents were recorded with the cellattached patch-clamp technique (Hamill et al., 1981). The electrodes were filled with (extracellular) solutions containing (in $\mathrm{mm}$ ) $150 \mathrm{NaCl}$, $2.5 \mathrm{KCl}, 1$ EDTA, $10 \mathrm{HEPBS}$ ( $N$-(2-hydroxyethyl) piperazine- $N^{\prime}(4-$ butanesulfonic acid)), 0.1 glycine, 1 glutamate and $0.1-0.5 \%$ DMSO (v/v) or 0.1 PAS (from DMSO stock), adjusted to $\mathrm{pH} 8(\mathrm{NaOH})$. Inward sodium currents were recorded after applying $+100 \mathrm{mV}$ through the recording pipette. Currents were amplified and low pass filtered at 10 $\mathrm{kHz}$ (Axopatch200B; 4-pole Bessel), sampled at 20 or $40 \mathrm{kHz}$ (PCI-6229, $M$ Series card, National Instruments) and written onto computer hard drives with QUB acquisition software (http://www.qub.buffalo.edu, Buffalo, NY).

\section{Single-channel current processing and analyses}

Data selection and preprocessing. Each digital file was displayed on computer monitors with QUB software and inspected visually for simultaneous openings, signal-to-noise ratios, high-frequency artifacts and baseline drift. In the conditions tested, due to low receptor desensitization rate constants $\left(<10 \mathrm{~s}^{-1}\right)$ and high open probability within clusters $\left(\mathrm{P}_{\mathrm{o}}, 0.5-0.9\right)$, records consisted of long, almost solid clusters of activity separated by zero-current periods lasting seconds (see Fig. 2). As a result, records originating from patches containing two or more active channels contained many superimposed clusters and were easily detected. These files were not considered for further processing or analyses. Although QUB can handle files with two or more active channels (provided these have similar kinetics), such multichannel records, become computationally expensive for minutes-long records. Instead, we aimed to obtain several high quality records with no apparent double openings for each condition tested. From this set of records, only those which required minimum processing were selected for kinetic analyses, mostly because it proved to be more time-consuming to "clean" a noisy file than to record a new one, particularly for the long files necessary for this study (average was $\sim 200,000$ events/file).

Furthermore, to correct errors due to occasional high-frequency artifacts, short periods of low signal-to-noise ratios, or baseline drift, the selected files were processed as follows. Brief (0.05-0.15 ms) current spikes were replaced with either closed- or open-level currents, matching the level of adjacent events, with the "erase" function in QUB. Longer (milliseconds to minutes) portions with low signal-to-noise ratios were deleted and the remaining flanking traces were preserved as separate segments within the processed file, to indicate discontinuity in the record. Finally, baseline drifts were corrected by resetting the baseline to zero-current levels, as necessary.

Modeling and kinetic analyses. Preprocessed data were idealized in QUB with the SKM algorithm after filtering to $12 \mathrm{kHz}$ with a Gaussian digital filter and after imposing a conservative dead time $(0.15 \mathrm{~ms}, 3$ or 6 samples) across all files. Results from this analysis were tabulated (supplemental Table 1, available at www.jneurosci.org as supplemental material) and reported as means \pm SEM for each condition. All subsequent analyses of idealized records were done in QUB with the MIL algorithm as described below.

First, we established the minimum number of states necessary to describe channel activity in each recorded file. This was done by adding closed and then open states, one-at-a-time, to an initial two-state (1C1O) model, while monitoring the associated increase in log likelihood values (LL). A best fit was one for which the LL no longer increased $>10$ LL units per added state. Each of the files considered had between $4 \times 10^{5}$ and $6 \times$ $10^{6}$ events and all were best fit by models having 5 closed and 3open states (5C3O). Time constants and relative areas of individual kinetic components were tabulated (supplemental Table 2, available at www.jneurosci.org as supplemental material) and reported as means \pm SEM for each condition.

As described in Results, we chose to represent the three open states with a single composite state, and used a simpler $5 \mathrm{C} 1 \mathrm{O}$ scheme to estimate rate constants. Of the 5 closed states resolved only the three shorter ones reside within clusters. For this reason, we and others have reasoned that the longest two closed states represent desensitized states (Lester and Jahr, 1992; Banke and Traynelis, 2003; Popescu and Auerbach, 2003; Popescu et al., 2004; Erreger et al., 2005; Dravid et al., 2008; Zhang et al., 2008). To establish the most likely position of desensitized states $\left(\mathrm{C}_{4}, \mathrm{C}_{5}\right)$ within the model, we fitted several $5 \mathrm{C} 1 \mathrm{O}$ schemes to all data globally within each condition (CTR, $n=7.2 \times 10^{6}$ events; PAS, $n=7$. $7 \times 10^{5}$ events) as shown in supplemental Methods, available at www. jneurosci.org as supplemental material. Briefly, this analysis was initiated with a linear 5C1O model and continued with models having increasingly branched structures. Best fits were decided based on a maximum LL criterion and both data sets (CTR and PAS) were best described with the model illustrated in Figure $4 A$. This model has the principal desensitized state $\mathrm{C}_{5}$ adjacent to the intracluster state $\mathrm{C}_{3}$, and the minor desensitized state $\mathrm{C}_{4}$, adjacent to the intracluster state $\mathrm{C}_{2}$. Rate constants estimated with this model for each file were tabulated (supplemental Table 3, available at www.jneurosci.org as supplemental material) and reported as means \pm SEM for each condition. 
A

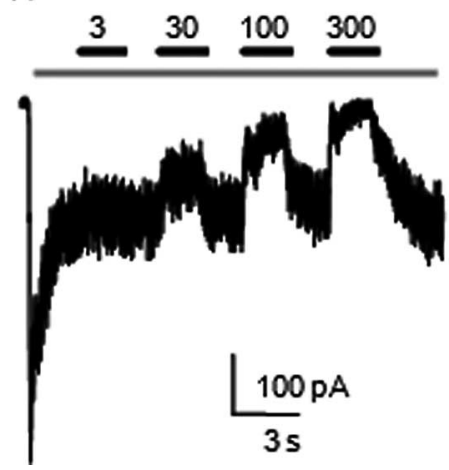

B

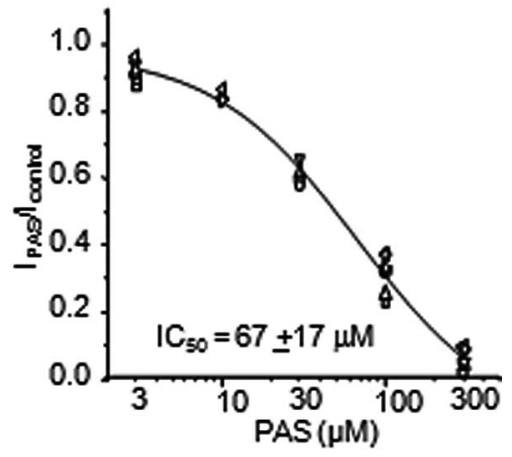

Figure 1. Neurosteroid inhibition of steady-state glutamate-elicited NMDA receptor currents $A$, Whole-cell response recorded from a HEK 293 cell expressing GluN1/GluN2A receptors. Bars indicate glutamate (1 mm) application (gray) and PAS ( $\mu \mathrm{m})$ coapplications (black). $\boldsymbol{B}$, Current levels measured after each PAS concentration were normalized to current levels immediately before each application. Symbols represent means of normalized values per each cell. Line represents the fit of the logistic function to means of normalized responses for each concentration: $3 \mu \mathrm{M}(n=7), 10 \mu \mathrm{M}(n=3), 30 \mu \mathrm{M}(n=4), 100 \mu \mathrm{M}(n=7)$, and 300 $\mu \mathrm{M}(n=7)$; Hill coefficient was $\mathrm{n}_{\mathrm{H}}=1.0 \pm 0.2$.

Differences in kinetic parameters between CTR and PAS were evaluated with two-tailed Student's $t$ tests assuming equal variance; were considered significant for $p<0.05$; and were expressed as: $\%$ change $=$ $((\mathrm{PAS} / \mathrm{CTR})-1) \times 100$.

\section{Simulations}

Macroscopic responses were simulated with the models indicated as the calculated time-dependent occupancies of open states and were expressed as fractional open probabilities. Pulses of glutamate were applied to 200 channels $(5.0 \pm 0.1 \mathrm{pA}$ each $)$ which at time 0 occupied the resting, unbound state $B_{1}$. The activation reaction was initiated with two identical and independent glutamate-binding steps, using glutamate association and dissociation rate constants previously measured for this preparation: $k_{+\mathrm{Glu}}=1.7 \times 10^{7} \mathrm{M}^{-1} \mathrm{~s}^{-1} ; k_{-\mathrm{Glu}}=60 \mathrm{~s}^{-1}$ (Popescu et al., 2004). In the presence of PAS, receptors were allowed to access the lower arm of the model, representing PAS-bound conformations, with rate constants $k_{+}=10^{5} \mathrm{~s}^{-1}$ and $k_{-}=100 \mathrm{~s}^{-1}$. These values were estimated based on previous reports on the kinetics of onset of and recovery from PAS inhibition (Petrovic et al., 2005). However, increasing or decreasing these rate constants up to two orders of magnitude had only minor effects on the kinetics of the macroscopic response and were consistent with the measured $\mathrm{IC}_{50}$.

\section{Notations}

Throughout this study we used the notations introduced by Shelley and Magleby (2008): $\mathrm{E}_{\mathrm{C}}$ and $\mathrm{E}_{\mathrm{O}}$ represent the exponential components of the closed and open interval distributions; $\tau_{\mathrm{E}}$ and $a_{\mathrm{E}}$ represent their corresponding time constant and relative areas; $\mathrm{C}_{n}$ and $\mathrm{O}_{n}$ represent closed and open states in the kinetic model; and state indices (n) increased with the state's distance from states of opposite conductance (Shelley and Magleby, 2008).

NMDA receptor subunits were identified with the nomenclature recently recommended by UPHR (Collingridge et al., 2009).

\section{Results}

\section{PAS reduces equilibrium NMDA receptor currents}

To determine the mechanism by which neurosteroids inhibit NMDA receptor responses, we compared the activity of individual receptor molecules in the presence and absence of the inhibitory neurosteroid PAS. In neural tissue, cells have specific complements of NMDA receptor subunits according to brain region, cell type and developmental period. Although the principal cells of the cortex and hippocampus express mainly GluN1, GluN2A and GluN2B subunits, the precise molecular composition of native NMDA receptors remains uncertain because these subunits can assemble as purely GluN1/GluN2A and GluN1/GluN2B het-

erodimers or as GluN1/GluN2A/GluN2B triheteromers (Cull-Candy and Leszkiewicz, 2004). Each of these molecular assemblies has distinct kinetic and pharmacological profiles (Vicini et al., 1998). For these reasons we studied HEK cells transiently transfected with GluN1 and GluN2A subunits, in which the molecular composition of each functional receptor is well defined.

In this preparation, we observed that whole-cell currents elicited by long applications of glutamate $(1 \mathrm{~mm}$, in the presence of $0.1 \mathrm{~mm}$ glycine) desensitized considerably and the equilibrium current was further reduced, in a reversible manner, by intermittent coapplication of PAS $(30-300 \mu \mathrm{M})$ (Fig. 1A). These measurements confirmed earlier findings that PAS inhibition of NMDA receptor responses was fast, reversible and concentrationdependent. Our calculated $\mathrm{IC}_{50}=67 \pm 17 \mu \mathrm{M}$ was close to previously reported values for recombinant GluN1/GluN2A receptors expressed in Xenopus oocytes and for GluN1/GluN2B receptors expressed in HEK cells (Irwin et al., 1994; Park-Chung et al., 1994; Malayev et al., 2002; Petrovic et al., 2005) (Fig. 1B). Because high concentrations of PAS inhibited almost completely steady-state activity $(91.2 \pm 0.5 \%$ inhibition for $0.3 \mathrm{~mm}$ PAS, $n=$ 7) we chose to investigate the activity of GluN1/GluN2A receptors in the presence of $0.1 \mathrm{~mm}$ PAS, expecting $\sim 60-70 \%$ reduction in equilibrium single-channel activity (measured macroscopic inhibition, $68 \pm 2 \%, n=7$ ).

\section{PAS lengthens NMDA receptor closures}

To focus specifically on PAS-dependent effects we examined the activity of individual GluN1/GluN2A receptors in the virtual absence of other extracellular modulatory influences: we used the cell-attached patch-clamp technique to preserve a physiological intracellular environment; we included $1 \mathrm{mM}$ EDTA in the recording pipette to eliminate trace amounts of free $\mathrm{Zn}^{2+}, \mathrm{Mg}^{2+}$, or $\mathrm{Ca}^{2+}$; and we recorded at $\mathrm{pH} 8$ to prevent receptor inhibition by protons (McBain and Mayer, 1994). Equilibrium singlechannel currents were elicited by including saturating concentrations of glutamate $(1 \mathrm{mM})$ and glycine $(0.1 \mathrm{mM})$ in the recording pipette along with $0.1-0.5 \%$ DMSO for controls (CTR) or 0.1 mM PAS and $0.1 \%$ DMSO for the neurosteroid-treated data set (PAS).

In these conditions, we obtained single-channel current records from several patches that contained only one active receptor (Fig. 2). In all these records, channels were of uniform conductance with no apparent sub- or supracurrent levels, as expected for currents carried mainly by sodium ions, in the absence of blocking divalent cations. After idealization of each trace, we evaluated single-channel current amplitudes and kinetic parameters for each record: equilibrium open probability $\left(\right.$ eq $\left.\mathrm{P}_{\mathrm{o}}\right)$, mean open time (MOT) and mean closed time (MCT) (supplemental Table 1, available at www.jneurosci.org as supplemental material). Based on these results, we concluded that 0.1 mM PAS had no significant effect on the observed single-channel current amplitude (CTR, $8.2 \pm 0.4 \mathrm{pA}, n=7$ vs PAS, $7.8 \pm 0.3$ $\mathrm{pA}, n=7, p>0.48$ ) but reduced drastically the equilibrium open probability of GluN1/GluN2A channels from $0.66 \pm 0.10$ (CTR) to $0.33 \pm 0.06$ (PAS), $p<0.001$ (Table 1 ). This $50 \%$ reduction in 
A
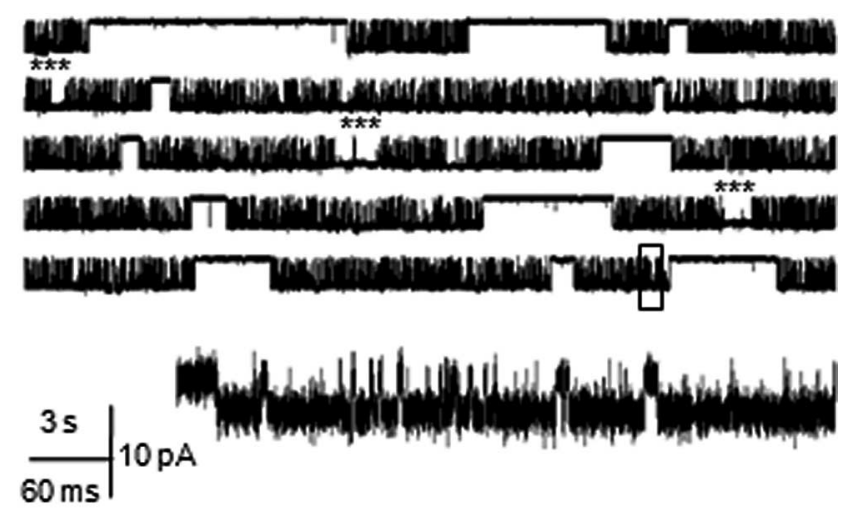

B

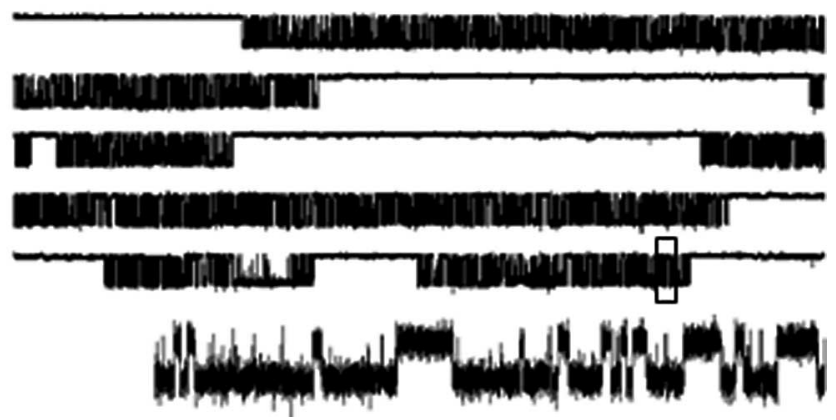

Figure 2. Steady-state single-channel activity of recombinant GluN1/GluN2A receptors. Currents were recorded from individual receptors isolated within a cell-attached membrane patch of HEK 293 cells in $\boldsymbol{A}$, control conditions ( $0.1 \%$ DMSO), and $\boldsymbol{B}$, with $0.1 \mathrm{~mm}$ PAS included in the recording pipette. In each panel, the five top traces illustrate $2.5 \mathrm{~min}$ of continuous receptor activity (displayed as $30 \mathrm{~s} /$ trace, filtered at $0.2 \mathrm{kHz}$ ); openings are downward. In the absence of calcium or other divalent cations (1 mм EDTA in the recording pipette), subconductance levels are absent. Boxed currents $(500 \mathrm{~ms}$ ) are illustrated below as a single trace on an expanded time scale, filtered at the analyzed bandwidth ( $12 \mathrm{kHz}$ ). Asterisks highlight sudden periods of high open probability (high mode), which, in the traces illustrated, were just seconds long.

eqP $\mathrm{P}_{\mathrm{o}}$ was due solely to a $\sim 450 \%$ increase in the mean closed time (CTR, $5.9 \pm 1.1 \mathrm{~ms}$ vs PAS, $32 \pm 12 \mathrm{~ms}, p<0.05)$ as the mean duration of channel openings was not changed significantly (CTR, $12.1 \pm 0.7 \mathrm{~ms}$ vs PAS, $10.4 \pm 1.1 \mathrm{~ms}, p>0.2)$. These results confirm that PAS is an allosteric inhibitor and reveal that it reduces the NMDA receptor currents exclusively by extending channel closures.

PAS extends specifically the long closed-time components To examine in further detail how PAS binding increases the mean channel closed time we examined the durations and relative areas of the individual components that make up the closed- and openinterval distributions. All records examined had distributions composed of 5 closed and 3 open components suggesting that PAS did not change the basic kinetic scheme of the NMDA receptor activation mechanism.

Consistent with the calculated increase in channel mean closed time, PAS-treated channels had closed time distributions that were shifted substantially toward longer durations, whereas the relative areas of individual components were only minimally affected (Fig. 3A,B; supplemental Table 2, available at www. jneurosci.org as supplemental material). Interestingly, rather than a general increase in the length of all closures, PAS induced significant changes only for the three longest closed timecomponents, $\tau_{\mathrm{EC} 3-5}$, which were $100-200 \%$ longer.

In contrast with this substantial and specific effect on closures, open-interval distributions for CTR and PAS data sets were virtually identical (Fig. 3C; supplemental Table 2, available at www.jneurosci.org as supplemental material). This was in agreement with the lack of effect of PAS on channel mean open time. The consistent finding that each record exhibited three separate open components, whereas the core gating mechanism of NMDA receptor has been demonstrated to consist of only two such components, was indicative of modal gating and implied that NMDA receptors retain the ability to switch between gating modes in the presence of PAS. Further, because open distributions were indistinguishable in the two data sets, we concluded that PAS did not change the kinetics of modal behavior (supplemental Table 1, available at www.jneurosci.org as supplemental material). This analysis established that PAS extends specifically the three longest time components in the NMDA receptor closed-time distribution with no statistically significant effect on channel openings. Next, we examined the PAS-induced changes in the NMDA receptor activation reaction.

\section{PAS induces NMDA receptors to accumulate in a desensitized state}

To evaluate PAS effects on the NMDA receptor activation reaction we selected the simplest scheme that captured the behaviors affected by PAS (Pugh and Andersen, 2008). Although NMDA receptor gating schemes postulate the presence of two coupled open states, based on our observation that PAS did not change the mean open time, the distribution of open intervals, or modal kinetics we reasoned that a simplified 5C1O model, in which all openings are represented as a single aggregate open state, was sufficient to describe the mechanism of PAS inhibition. This simplification was also warranted by previous analyses suggesting that in each mode, the two open states are most probably vicinal (Popescu and Auerbach, 2003; Auerbach and Zhou, 2005).

However, we should note that the low frequency of modal transitions prevented us from establishing whether receptors which gated in a particular mode were differentially inhibited by PAS. If this were the case, the results obtained by fitting the $5 \mathrm{C} 1 \mathrm{O}$ model to entire single-channel current files would reflect a weighted average of the PAS effects on the three possible modes. Still, because the frequencies with which the three modes occurred in the two data sets were similar, such hypothetical differential sensitivity would not distort our conclusions regarding PAS-induced changes in the activation reaction (supplemental Table 2, available at www.jneurosci.org as supplemental material).

Based on a log-likelihood criterion for the most probable arrangement of closed states within the model, we used a reaction scheme that had the two longest-lived closed states located off-pathway (Fig. $4 A$; supplemental Fig. 1, available at www.jneurosci.org as supplemental material). In the presence of saturating concentrations of glutamate and glycine, all NMDA receptor isoforms investigated so far produce clusters of activity that are statistically well described with reaction mechanisms composed of 3 closed and 2 open states (Banke and Traynelis, 2003; Popescu and Auerbach, 2003; Popescu et al., 2004; Auerbach and Zhou, 2005; Erreger et al., 2007; Dravid et al., 2008). Recently, this core mechanism was extended to include desensitized states (D), which were defined as high-affinity, long-lived ( $>10 \mathrm{~ms}$ ), nonconductive states which branch away from the main activation pathway (Dravid 
Table 1. Kinetic parameters of single GluN1/GluN2A receptor activity in cell-attached patches

\begin{tabular}{llllllr}
\hline & $\begin{array}{l}\text { Duration } \\
(\mathrm{min})\end{array}$ & $\begin{array}{l}\text { Events } \\
\left(\times 10^{6}\right)\end{array}$ & $\begin{array}{l}\text { Amplitude } \\
(\mathrm{pA})\end{array}$ & $\mathrm{eqP}_{0}$ & $\begin{array}{l}\text { MCT } \\
(\mathrm{ms})\end{array}$ & \multicolumn{1}{c}{$\begin{array}{l}\text { M0T } \\
(\mathrm{ms})\end{array}$} \\
\hline Control $(n=7)$ & 319 & 20.4 & $8.2 \pm 0.4$ & $0.66 \pm 0.10$ & $5.9 \pm 1.1$ & $12.1 \pm 0.7$ \\
PAS $(n=7)$ & 251 & 6.9 & $7.8 \pm 0.3$ & $0.33 \pm 0.06$ & $32 \pm 12$ & $10.4 \pm 1.1$ \\
$p$ & & & $p>0.48$ & $\begin{array}{c}p<0.001 \\
-50 \%\end{array}$ & $\begin{array}{c}p<0.05 \\
+447 \%\end{array}$ & $p>0.2$ \\
\% change & & & & $-50 \%$ & \\
\hline
\end{tabular}

A

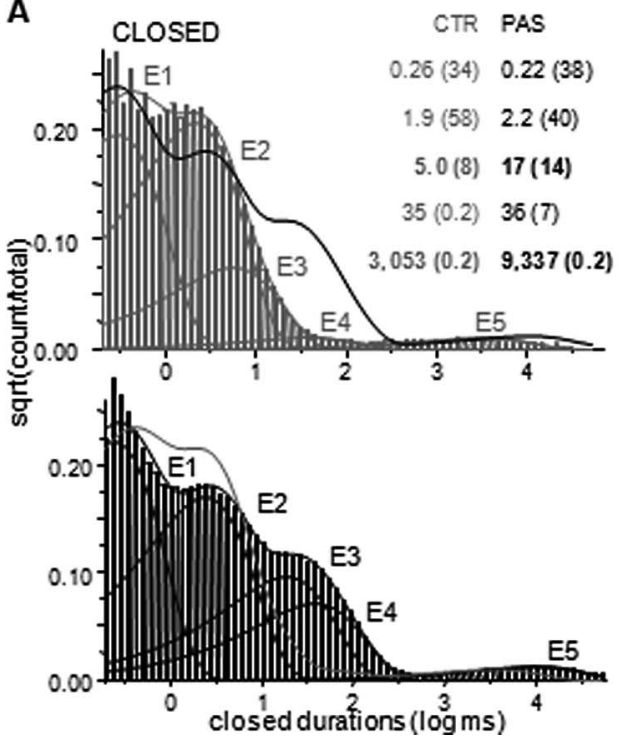

B
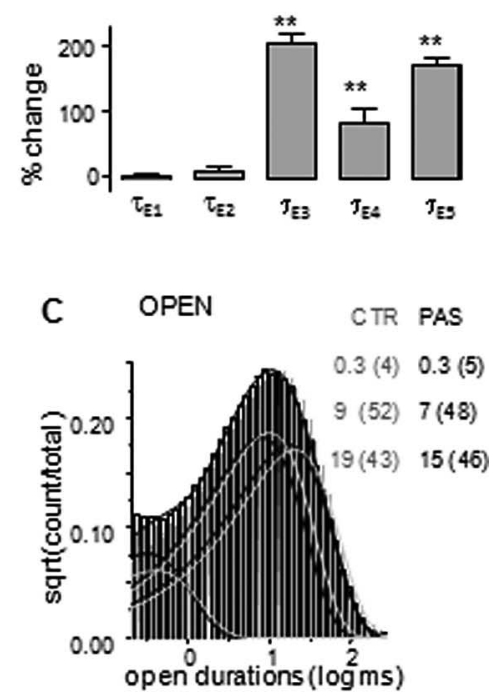

Figure 3. PAS lengthens three closed time components with no effect on open durations. $\boldsymbol{A}$, Closed-interval distributions for control (top, gray) with superimposed pdf for PAS (black line) and for PAS (bottom, black) with superimposed pdf for control (gray). Each distribution has five exponential components E1-E5 (thin lines). Results are for two records, portions of which are illustrated in Figure 1; analyzed events: $5.8 \times 10^{6}$ (CTR) and $2.0 \times 10^{6}$ (PAS). $\boldsymbol{B}$, Cumulative results (mean \pm SEM) show that PAS treatment increases the durations of two separate closed time components, $\tau_{\mathrm{E} 3}$ and $\left.\tau_{\mathrm{E} 5}{ }^{* *} p<0.0004\right)$, and to a lesser degree, $\tau_{\mathrm{E} 4}$. CTR: $n=7,2.7 \times 10^{7}$ events; PAS: $n=7,8.5 \times 10^{6}$ events. C, Overlaid open-interval distributions for the records analyzed in $\boldsymbol{A}$ and illustrated in Figure 1: (TR, gray, and PAS-treated, black. Both distributions have three components of similar durations and amplitudes (inset).

et al., 2008; Zhang et al., 2008). With this extended model, the entire sequence of events in any single-channel record, clusters and gaps, can be described with models having a total of 5 closed states ( 3 within clusters and 2 representing the gaps in-between) (Fig. 4A).

To identify the PAS-sensitive rate constants we used this extended 5C2O gating scheme to estimate rate constants for the postulated transitions separately for each record; the means for the seven records in each data set are illustrated above the arrow for the respective transition (Fig. 4A; supplemental Table 3, available at www. jneurosci.org as supplemental material). We found that the largest statistically significant kinetic changes observed in the PAS data set occurred for receptor transitions into and from state $\mathrm{C}_{3}$ : the microscopic desensitization transition $\left(\mathrm{C}_{3} \rightarrow \mathrm{C}_{5}\right)$ and the reverse reaction $\left(\mathrm{C}_{5} \rightarrow \mathrm{C}_{3}\right)$ were $50-100 \%$ slower; the $\mathrm{C}_{3} \rightarrow \mathrm{C}_{2}$ activating (toward Open) transition was $\sim 50 \%$ slower; and the reverse $\mathrm{C}_{2} \rightarrow \mathrm{C}_{3}$ deactivating (away from Open) transition was $\sim 150 \%$ faster (Fig. $4 B$ ). In terms of relative free-energy, the observed inhibition results from an increased stability of closed states located distal to the active conformations (supplemental Fig. 1, available at www.jneurosci.org as supplemental material). At equilibrium, $0.1 \mathrm{~mm}$ PAS bends the energy profile of the NMDA receptor activation reaction causing $\sim 150 \%$ increase in the occupancy of the main desensitized state $\mathrm{C}_{5}$, mostly at the expense of open states occupancies (Fig. 4C).

\section{PAS increases macroscopic NMDA} receptor desensitization

A major prediction of this proposed mechanism was that NMDA receptor currents would desensitize more deeply in the presence of PAS. Because such an effect of PAS on NMDA receptor responses has not been reported previously, we went on to test this prediction by recording nonequilibrium macroscopic responses from $\mathrm{HEK}$ 293 cells expressing GluN1/GluN2A receptors during long ( $5 \mathrm{~s}$ ) applications of glutamate and glycine (CTR) or glutamate, glycine and $0.1 \mathrm{~mm}$ PAS (PAS) (Fig. $5 A)$. To eliminate zinc-dependent effects we included $0.01 \mathrm{~mm}$ EDTA in the extracellular solutions. Results showed that indeed, when evaluated as the ratio of the steady-state current level to the peak current $\left(I_{\mathrm{ss}} / I_{\mathrm{pk}}\right)$, macroscopic desensitization was $83 \%$ deeper in the presence of $0.1 \mathrm{~mm}$ PAS, with the $I_{\mathrm{ss}} / I_{\mathrm{pk}}$ ratio decreasing from $0.48 \pm 0.07$ (CTR) to $0.08 \pm 0.03$ (PAS), $n=3, p<0.02$ (supplemental Table 4, available at www.jneurosci.org as supplemental material).

Similar results were obtained in cultured rat cortical neurons suggesting that PAS may inhibit responses from native receptors with the same mechanism. Although the neuronal preparation we used expresses most likely both GluN2A and GluN2B subunits, the PAS effect on the macroscopic response was comparable to that measured for recombinant GluN1/ GluN2A receptors. The $I_{\mathrm{ss}} / I_{\mathrm{pk}}$ ratio was significantly and substantially reduced by $0.1 \mathrm{~mm}$ PAS, from $0.87 \pm 0.01$ (CTR) to $0.21 \pm 0.02$ (PAS), $n=3, p<0.0001$ (Fig. $5 A$; supplemental Table 4 , available at www.jneurosci.org as supplemental material). Based on these results we concluded that the kinetic model derived from single-channel currents of recombinant receptors captured the mechanism of the PAS inhibition and may represent an adequate model for the effects of PAS on native receptors as well.

Keeping in mind that our model was derived from receptors situated in intact membrane patches whereas macroscopic measurements are necessarily obtained after disrupting the integrity of the plasma membrane we expected quantitative differences between the predicted and measured waveforms. To evaluate the differences between the effects of PAS on receptors which reside in intact or punctured cells we turned to Monte Carlo simulations.

\section{PAS induces desensitization of activated receptors}

It has been noted for more than a decade that in addition to the intrinsic desensitization of macroscopic responses which mirrors the increasing occupancy of long-lived closed states, additional response desensitization occurs after disruption of cellular integrity through calcium-dependent mechanisms (Rosenmund et al., 1995; Krupp et al., 2002; Rycroft and Gibb, 2004). This further decrease in steady-state current levels reflects shorter mean open durations and more frequent visits of microscopic desensitized 
states (Zhang et al., 2008). We accounted for these expected changes accordingly, by setting the microscopic desensitization rate constant $k_{\mathrm{C} 3-\mathrm{C} 5}$ and the apparent closing rate constant $k_{\mathrm{O}-\mathrm{C} 1}$ to values twofold higher than those measured in our cellattached preparation (supplemental Fig. 2 , available at www.jneurosci.org as supplemental material). Thus, $k_{\mathrm{C} 3-\mathrm{C} 5}$ was increased in the CTR arm, from $7 \mathrm{~s}^{-1}$ to 14 $\mathrm{s}^{-1}$ and in the PAS arm, from $1.5 \mathrm{~s}^{-1}$ to $3 \mathrm{~s}^{-1}$; whereas $k_{\mathrm{O}-\mathrm{C} 1}$ was increased to $250 \mathrm{~s}^{-1}$ in both tiers (Fig. 5B, underlined values). We reasoned that these adjustments should approximate channel behaviors in preparations where the membrane integrity was compromised, such as the whole-cell or excised-patch preparations.

To simulate glutamate-elicited nonequilibrium responses, the steady-state models were amended to include glutamate binding steps: $k_{+}=1.7 \times 10^{7} \mathrm{M}^{-1}$ $\mathrm{s}^{-1} ; k_{-}=60 \mathrm{~s}^{-1}$, as described previously (Popescu et al., 2004). Currents were calculated as time-dependent open state occupancies, after a square step into $1 \mathrm{~mm}$ glutamate, starting from $100 \%$ occupancy of the resting, unliganded state $\mathrm{B}_{1}$ (Fig. $5 B)$. As expected, this procedure reproduced closely the main features of the GluN1/GluN2A whole-cell response measured in HEK cells (compare gray traces in left panels of Fig. $5 A, C$ ): the decay of the macroscopic trace during agonist application, $\tan _{\mathrm{D}}$, was $1.5 \pm$ $0.2 \mathrm{~s}$ for experimental currents and $1.7 \mathrm{~s}$ for simulated traces; the ratio of steady-state current level relative to peak level $\left(I_{\mathrm{ss}} / I_{\mathrm{pk}}\right)$ was $0.48 \pm 0.07$ for experimental traces versus 0.51 for simulated responses (supplemental Table 4, available at www.jneurosci.org as supplemental material). Importantly, these simulations allowed us to predict the fraction of GluN1/GluN2A receptors contributing to the peak current in the whole-cell preparation, $\mathrm{pkP}_{\mathrm{o}}$ $=0.73$, a parameter difficult to measure directly. As expected this value is higher than that estimated experimentally, due to the absence of divalent cations (1 mM EDTA) and low proton levels $(\mathrm{pH}$ 8), conditions expected to increase channel open probabilities.

Consistent with previous reports of use-dependent inhibition, appending glutamate binding steps to the model in Figure $4 A$, which would simulate glutamate activation of PAS-equilibrated receptors, did not reproduce the shape of the experimental response. Instead, the macroscopic response in the presence of PAS was closely replicated with the tiered model illustrated in Figure $5 B$, which represents PAS binding to glutamate-activated receptors. This result is in agreement with reports by the Vyklicky group showing that: PAS reduces NMDA receptor currents only when applied simultaneously with or subsequently to glutamate; PAS decelerates glutamate dissociation; and NMDA responses recover from PAS inhibition with slow and complex kinetics (Petrovic et al., 2005). The tiered model accounted for these experimental findings and approximated the effects of PAS on the kinetics of whole-cell responses. Thus we concluded that the tiered model captures the essential features of NMDA receptor inhibition by pregnanolone sulfate. These same simulations were
B
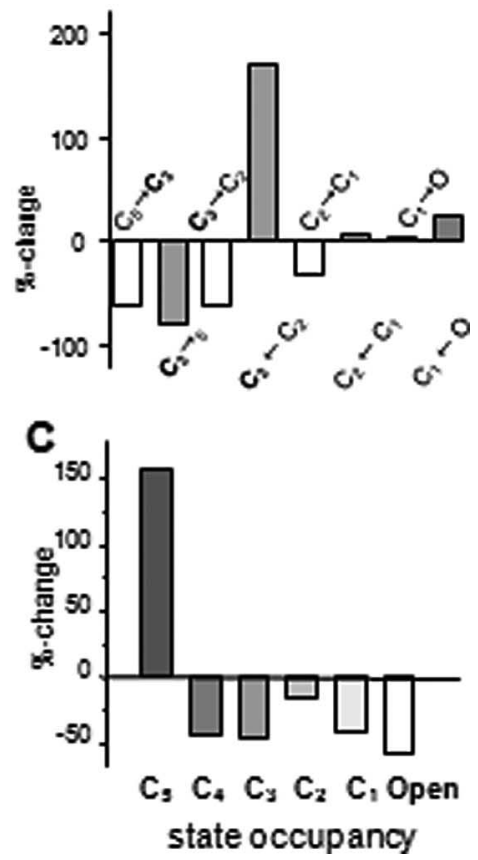

Figure 4. PAS-bound receptors accumulate in a desensitized state. $A$, Kinetic schemes for NMDA receptor gating derived from steady-state single-channel current activity in cell-attached patches. All states represent receptors fully occupied with glutamate transitions are omitted. The largest changes are observed for rates entering or leaving the $C_{3}$ closed state (bold). C, Bar graph illustrates that PAS induces receptors to accumulate in a desensitized state $\left(\right.$ state $C_{5}$ ) at the expense of open-state occupancies.

repeated with rates representative for cell-attached receptors, as illustrated in Figure 5B. Based on these results it is expected that PAS will have similar effects on NMDA receptor responses, whether the receptors reside in intact or whole-cell preparations (Fig. 5C, right; supplemental Table 4, available at www.jneurosci.org as supplemental material).

Last, we wanted to determine how 0.1 mM PAS would influence the response of synaptic NMDA receptors. It has been proposed that of the three gating modes described for recombinant receptors, synaptic receptors adopt most-likely the L-mode kinetics, characterized by a shorter mean open time than measured in this study (Atasoy et al., 2008; Zhang et al., 2008). For this reason, to simulate synaptic responses we increased, in both arms of the model, the closing rate constants $k_{\mathrm{O}-\mathrm{C} 1}$ to $333 \mathrm{~s}^{-1}$ (supplemental Fig. 2, available at www.jneurosci.org as supplemental material). These simulations suggested that $0.1 \mathrm{~mm}$ PAS would reduce only minimally the peak of the NMDA receptor-mediated epsc but its effect on current relaxation would be highly dependent on the rate with which glutamate can dissociate from PASbound receptors (Fig. 5E).

\section{Discussion}

Neurosteroids are powerful modulators of neuronal excitability which are synthesized locally by nervous tissue from cholesterol or from circulating steroids. Their endogenous levels fluctuate rapidly with behaviors (Remage-Healey et al., 2008) as well as with physiologic and pathologic states (Uzunova et al., 1998; Baulieu et al., 2001; Mellon and Griffin, 2002a; Roglio et al., 2008). Controlled local synthesis of neuroactive steroid metabolites participates in neural development, cognitive processes and 
A

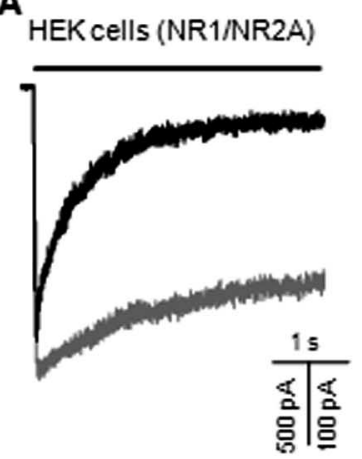

C

whole-cell model

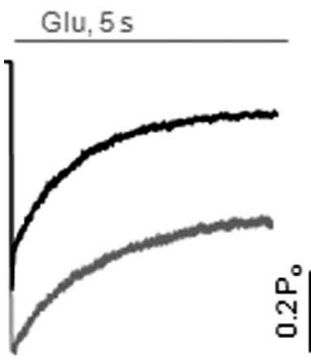

Cortical neurons

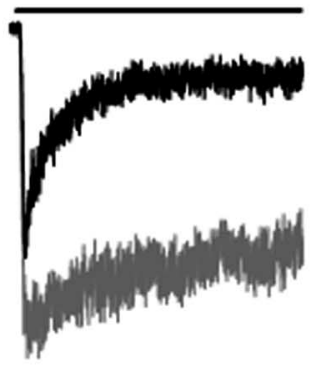

cell-attached model

Glu, 10 s

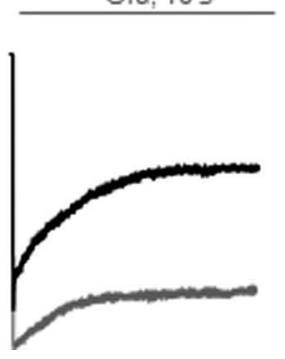

B

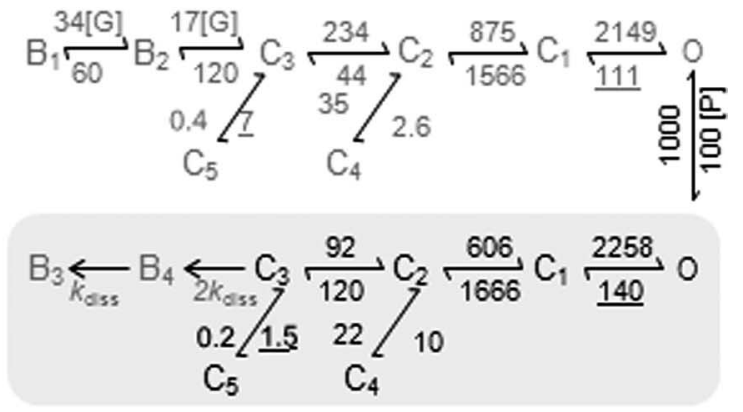

D

whole-cell model

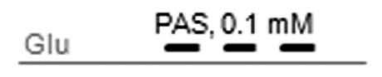

cell-attached, L-model

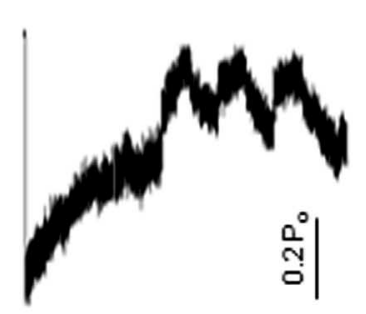

$2 \mathrm{~s}$

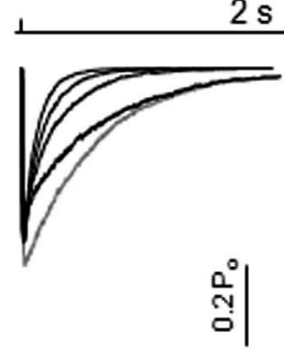

Figure 5. PAS promotes desensitization of activated NMDA receptors. A, Whole-cell current traces recorded during $5 \mathrm{~s}$ application of agonists (gray) or agonists and $0.1 \mathrm{~mm}$ PAS (black) from HEK 293 cells expressing recombinant receptors (left) and from cultured rat cortical neurons (15 days in vitro; right). $\boldsymbol{B}$, Tiered model used to simulate nonequilibrium NMDA receptor responses in cell-attached patches; underlined rate constants $\left(C_{3} \rightarrow C_{5}\right.$ and $\left.0 \rightarrow C_{1}\right)$ were increased twofold (see Results) to simulate whole-cell responses. In this model, glutamate binds to PAS-free receptors $B_{1}$ and $B_{2}$ with rates scaled by glutamate concentration, [G]; the upper tier (gray) represents activation of PAS-free receptors and the lower tier (black) represents the gating of PAS-bound receptors in the presence of $0.1 \mathrm{~mm} P A S$. In this model, PAS binds only to open receptors, with rates proportional to PAS concentration, $[\mathrm{P}]=0.1 \mathrm{~mm}$, and glutamate dissociates from PAS-bound receptors with undetermined rate constants, $k_{\text {diss }}$. C, Simulated whole-cell (left) and cell-attached (right) nonequilibrium macroscopic responses elicited with agonists (gray) or agonists and $0.1 \mathrm{~mm}$ PAS (black). D, Simulated whole-cell response during $25 \mathrm{~s}$ application of agonists ( $1 \mathrm{~mm}$ Glu, $0.1 \mathrm{~mm}$ Gly) and intermittent $3 \mathrm{~s}$ coapplications of PAS ( $0.1 \mathrm{~mm})$. E, Postsynaptic NMDA receptor responses were simulated with the model illustrated in $\boldsymbol{B}$, where the closing rate constants, $0 \rightarrow C_{1}$, were adjusted to $333 \mathrm{~s}^{-1}$ in both arms to represent low mode receptors believed to generate synaptic responses, and the glutamate dissociation rate from PAS-bound receptors, $k_{\text {diss, }}$, was varied. Simulations suggested that the peak amplitude of the response is insensitive to $k_{\text {diss, }}$ whereas the relaxation kinetics is faster in the presence of PAS with decay times of $320 \mathrm{~s}^{-1}$ in the absence of PAS (CTR, gray) and 62, 100, 142, and $300 \mathrm{~s}^{-1}$, respectively, when $k_{\text {diss }}$ was set to $60,30,15$, and $5 \mathrm{~s}^{-1}$ (black lines).

mood control (Mellon and Griffin, 2002b; Mellon, 2007). The concentrations of neurosteroids in vivo and whether these reach pharmacological levels even locally remain controversial (Schumacher et al., 2008). However, due to their indisputable effects on excitability and neurodegeneration, neurosteroids remain actively investigated as therapies for mood disorders, chronic pain and neurodegenerative conditions (Stoffel-Wagner, 2003; Charalampopoulos et al., 2006; Eser et al., 2006; MacKenzie et al., 2007; Roglio et al., 2008; Schumacher et al., 2008).

In the present study, we examined the effects of pregnanolone sulfate on the equilibrium single-channel activity of solitary GluN1/GluN2A receptors isolated within cell-attached membrane patches. Currents were elicited with saturating levels of glutamate and glycine and in the virtual absence of other allosteric modulators or blockers. In these conditions, $0.1 \mathrm{~mm}$ PAS reduced the open probability of NMDA receptors by selectively increasing the mean duration of closures with no observable effect on the mean duration of openings or on the mean singlechannel current amplitude. These results were in quantitative agreement with previously measured inhibitory effects of PAS on NMDA receptor-mediated responses: PAS $(0.1 \mathrm{~mm})$ inhibited whole-cell NMDA receptor currents by $60-70 \%$ in native or recombinant preparations (Park-Chung et al., 1994; Park-Chung et al., 1997; Yaghoubi et al., 1998; Petrovic et al., 2005; Stastna et al., 2009) and decreased calcium fluxes by $\sim 70 \%$ in rat hippocampal and cortical neurons (Irwin et al., 1994; Shirakawa et al., 2002).
Consistent with these reports we observed a twofold reduction in the equilibrium single-channel open probability of GluN1/ GluN2A receptors in the presence of $0.1 \mathrm{~mm}$ PAS.

Through more detailed analysis of interval durations, we identified three separate closed time-components within the closed-interval distribution which were selectively and substantially lengthened in the presence of PAS: $\tau_{\mathrm{c} 3}, \tau_{\mathrm{c} 4}$, and $\tau_{\mathrm{c} 5}$. In contrast, PAS had no observable effect on the distribution of open time-components. Based on these results we conclude that PAS is an allosteric NMDA receptor modulator that does not change the basic structure of the NMDA receptor activation mechanism but increases the time spent by receptors in long-lived agonist-bound nonconductive conformations. These findings are completely model-independent and argue strongly that PAS inhibits NMDA receptor responses by increasing the lifetimes of microscopic desensitized states.

Unlike time-components whose durations and amplitudes describe factually the distributions of measured interval durations, rate constants for transitions between states are estimated by fitting user-defined kinetic models to the sequence of closed and open intervals within single-channel records and thus, are inextricably dependent not only on the number of closed and open states postulated in the model but also on the arrangement of states within the chain (Colquhoun and Hawkes, 1981). For NMDA receptors, several kinetic models have been proposed recently (Banke and Traynelis, 2003; Popescu and Auerbach, 
2003; Auerbach and Zhou, 2005; Schorge et al., 2005). For the present study, we selected the simplest kinetic model that described with highest likelihood the totality of observed events within each recorded file (Fig. $4 A$ ). Fitting this model to the entire sequence of events in each file was justified by our selection of records originating from only one active channel and allowed us to attribute mechanistic meaning to closed intervals which reside outside clusters (Colquhoun and Hawkes, 1990). Based on the rate constants estimated with this model we propose that PAS reduced the measured single-channel open probability of NMDA receptors by increasing the stabilities of closed states distal to open states and thus causing receptors to accumulate in desensitized conformations.

Further, we were able to describe PAS-inhibition of nonstationary currents with the sequential model represented in Figure $5 B$.This model postulates that resting receptors have low affinity for PAS such that on exposure to glutamate they transition with "control" rates toward active conformations, which have increased affinity for PAS. After PAS binding, receptors drift slowly into desensitized conformations, mostly at the expense of open state occupancies. Importantly, the model predicts that the magnitude of the observed inhibitory effect will depend on the duration of glutamate application, being more prominent for equilibrium currents than for the initial peak response.

In this study we have identified the rate constants within the reaction mechanism of NMDA receptors that are sensitive to PAS binding and we have measured these rates in the presence of 0.1 mM PAS. However, it is important to emphasize that how steeply sensitive these rates are to PAS concentrations remains to be determined. Likewise, it will be important to measure PAS association and dissociation rate constants for glutamate-bound receptors and the glutamate dissociation rate constant from PASbound receptors. Our simulations suggested that the latter may play a significant role in determining the effect of PAS on the NMDA-receptor mediated synaptic response.

In summary, we show that PAS causes NMDA receptors to reside for longer periods in nonconducting conformations. Based on these observations and kinetic modeling of single-channel data we propose that PAS decreases NMDA receptor-mediated currents by binding to active receptors and subsequently siphoning these into silent, desensitized states. These new findings add mechanistic insight into the potential use of pregnanolone derivatives as therapeutic agents, while at the same time stressing the need for further characterization of the interactions between PAS and NMDA receptors.

\section{References}

Atasoy D, Ertunc M, Moulder KL, Blackwell J, Chung C, Su J, Kavalali ET (2008) Spontaneous and evoked glutamate release activates two populations of NMDA receptors with limited overlap. J Neurosci 28:10151-10166.

Auerbach A, Zhou Y (2005) Gating reaction mechanisms for NMDA receptor channels. J Neurosci 25:7914-7923.

Banke TG, Traynelis SF (2003) Activation of NR1/NR2B NMDA receptors. Nat Neurosci 6:144-152.

Baulieu EE, Robel P, Schumacher M (2001) Neurosteroids: beginning of the story. Int Rev Neurobiol 46:1-32.

Charalampopoulos I, Alexaki VI, Tsatsanis C, Minas V, Dermitzaki E, Lasaridis I, Vardouli L, Stournaras C, Margioris AN, Castanas E, Gravanis A (2006) Neurosteroids as endogenous inhibitors of neuronal cell apoptosis in aging. Ann N Y Acad Sci 1088:139-152.

Collingridge GL, Olsen RW, Peters J, Spedding M (2009) A nomenclature for ligand-gated ion channels. Neuropharmacology 56:2-5.

Colquhoun D, Hawkes AG (1981) On the stochastic properties of single ion channels. Proc R Soc Lond B Biol Sci 211:205-235.
Colquhoun D, Hawkes AG (1990) Stochastic properties of ion channel openings and bursts in a membrane patch that contains two channels: evidence concerning the number of channels present when a record containing only single openings is observed. Proc R Soc Lond B Biol Sci 240:453-477.

Cull-Candy SG, Leszkiewicz DN (2004) Role of distinct NMDA receptor subtypes at central synapses. Sci STKE 2004:re16.

Dravid SM, Prakash A, Traynelis SF (2008) Activation of recombinant NR1/ NR2C NMDA receptors. J Physiol 586:4425-4439.

Erreger K, Dravid SM, Banke TG, Wyllie DJ, Traynelis SF (2005) Subunitspecific gating controls rat NR1/NR2A and NR1/NR2B NMDA channel kinetics and synaptic signalling profiles. J Physiol 563:345-358.

Erreger K, Geballe MT, Kristensen A, Chen PE, Hansen KB, Lee CJ, Yuan H, Le P, Lyuboslavsky PN, Micale N, Jørgensen L, Clausen RP, Wyllie DJ, Snyder JP, Traynelis SF (2007) Subunit-specific agonist activity at NR2A-, NR2B-, NR2C-, and NR2D-containing N-methyl-D-aspartate glutamate receptors. Mol Pharmacol 72:907-920.

Eser D, Schüle C, Baghai TC, Romeo E, Uzunov DP, Rupprecht R (2006) Neuroactive steroids and affective disorders. Pharmacol Biochem Behav 84:656-666.

Gibb AJ, Colquhoun D (1991) Glutamate activation of a single NMDA receptor-channel produces a cluster of channel openings. Proc Biol Sci 243:39-45.

Gibb AJ, Colquhoun D (1992) Activation of N-methyl-D-aspartate receptors by L-glutamate in cells dissociated from adult rat hippocampus. J Physiol 456:143-179.

Gibbs TT, Russek SJ, Farb DH (2006) Sulfated steroids as endogenous neuromodulators. Pharmacol Biochem Behav 84:555-567.

Hamill OP, Marty A, Neher E, Sakmann B, Sigworth FJ (1981) Improved patch-clamp techniques for high-resolution current recording from cells and cell-free membrane patches. Pflugers Arch 391:85-100.

Howe JR, Colquhoun D, Cull-Candy SG (1988) On the kinetics of largeconductance glutamate-receptor ion channels in rat cerebellar granule neurons. Proc R Soc Lond B Biol Sci 233:407-422.

Howe JR, Cull-Candy SG, Colquhoun D (1991) Currents through single glutamate receptor channels in outside-out patches from rat cerebellar granule cells. J Physiol 432:143-202.

Irwin RP, Lin SZ, Rogawski MA, Purdy RH, Paul SM (1994) Steroid potentiation and inhibition of $N$-methyl-D-aspartate receptor-mediated intracellular $\mathrm{Ca}++$ responses: structure-activity studies. J Pharmacol Exp Ther 271:677-682.

Krupp JJ, Vissel B, Thomas CG, Heinemann SF, Westbrook GL (2002) Calcineurin acts via the C-terminus of NR2A to modulate desensitization of NMDA receptors. Neuropharmacology 42:593-602.

Lapchak PA (2006) 3alpha-OL-5-beta-pregnan-20-one hemisuccinate, a steroidal low-affinity NMDA receptor antagonist improves clinical rating scores in a rabbit multiple infarct ischemia model: synergism with tissue plasminogen activator. Exp Neurol 197:531-537.

Lester RA, Jahr CE (1992) NMDA channel behavior depends on agonist affinity. J Neurosci 12:635-643.

MacKenzie EM, Odontiadis J, Le Mellédo JM, Prior TI, Baker GB (2007) The relevance of neuroactive steroids in schizophrenia, depression, and anxiety disorders. Cell Mol Neurobiol 27:541-574.

Malayev A, Gibbs TT, Farb DH (2002) Inhibition of the NMDA response by pregnenolone sulphate reveals subtype selective modulation of NMDA receptors by sulphated steroids. Br J Pharmacol 135:901-909.

McBain CJ, Mayer ML (1994) N-Methyl-D-aspartic acid receptor structure and function. Physiol Rev 74:723-760.

Mellon SH (2007) Neurosteroid regulation of central nervous system development. Pharmacol Ther 116:107-124.

Mellon SH, Griffin LD (2002a) Neurosteroids: biochemistry and clinical significance. Trends Endocrinol Metab 13:35-43.

Mellon SH, Griffin LD (2002b) Synthesis, regulation, and function of neurosteroids. Endocr Res 28:463.

Misonou H, Trimmer JS (2005) A primary culture system for biochemical analyses of neuronal proteins. J Neurosci Methods 144:165-173.

Paoletti P, Neyton J (2007) NMDA receptor subunits: function and pharmacology. Curr Opin Pharmacol 7:39-47.

Park-Chung M, Wu FS, Farb DH (1994) 3alpha-Hydroxy-5 beta-pregnan20-one sulfate: a negative modulator of the NMDA-induced current in cultured neurons. Mol Pharmacol 46:146-150.

Park-Chung M, Wu FS, Purdy RH, Malayev AA, Gibbs TT, Farb DH (1997) 
Distinct sites for inverse modulation of $N$-methyl-D-aspartate receptors by sulfated steroids. Mol Pharmacol 52:1113-1123.

Petrovic M, Sedlacek M, Horak M, Chodounska H, Vyklický L Jr (2005) 20-Oxo-5 \{beta\}-pregnan-3\{alpha\}-yl sulfate is a use-dependent NMDA receptor inhibitor. J Neurosci 25:8439-8450.

Popescu G, Auerbach A (2003) Modal gating of NMDA receptors and the shape of their synaptic response. Nat Neurosci 6:476-483.

Popescu G, Robert A, Howe JR, Auerbach A (2004) Reaction mechanism determines NMDA receptor response to repetitive stimulation. Nature 430:790-793.

Pugh EN Jr, Andersen OS (2008) Models and mechanistic insight. J Gen Physiol 131:515-519.

Remage-Healey L, Maidment NT, Schlinger BA (2008) Forebrain steroid levels fluctuate rapidly during social interactions. Nat Neurosci 11:1327-1334.

Roglio I, Giatti S, Pesaresi M, Bianchi R, Cavaletti G, Lauria G, Garcia-Segura LM, Melcangi RC (2008) Neuroactive steroids and peripheral neuropathy. Brain Res Rev 57:460-469.

Rosenmund C, Feltz A, Westbrook GL (1995) Calcium-dependent inactivation of synaptic NMDA receptors in hippocampal neurons. J Neurophysiol 73:427-430.

Rycroft BK, Gibb AJ (2004) Inhibitory interactions of calcineurin (phosphatase 2B) and calmodulin on rat hippocampal NMDA receptors. Neuropharmacology 47:505-514.

Schorge S, Elenes S, Colquhoun D (2005) Maximum likelihood fitting of single channel NMDA activity with a mechanism composed of independent dimers of subunits. J Physiol 569:395-418.

Schumacher M, Liere P, Akwa Y, Rajkowski K, Griffiths W, Bodin K, Sjövall J, Baulieu EE (2008) Pregnenolone sulfate in the brain: a controversial neurosteroid. Neurochem Int 52:522-540.

Shelley C, Magleby KL (2008) Linking exponential components to kinetic states in Markov models for single-channel gating. J Gen Physiol 132:295-312.

Shirakawa H, Katsuki H, Kume T, Kaneko S, Ito J, Akaike A (2002) Regula- tion of $N$-methyl-D-aspartate cytotoxicity by neuroactive steroids in rat cortical neurons. Eur J Pharmacol 454:165-175.

Stastna E, Chodounska H, Pouzar V, Kapras V, Borovska J, Cais O, Vyklicky L Jr (2009) Synthesis of C3, C5, and C7 pregnane derivatives and their effect on NMDA receptor responses in cultured rat hippocampal neurons. Steroids 74:256-263.

Stern P, Cik M, Colquhoun D, Stephenson FA (1994) Single channel properties of cloned NMDA receptors in a human cell line: comparison with results from Xenopus oocytes. J Physiol 476:391-397.

Stoffel-Wagner B (2003) Neurosteroid biosynthesis in the human brain and its clinical implications. Ann N Y Acad Sci 1007:64-78.

Uzunova V, Sheline Y, Davis JM, Rasmusson A, Uzunov DP, Costa E, Guidotti A (1998) Increase in the cerebrospinal fluid content of neurosteroids in patients with unipolar major depression who are receiving fluoxetine or fluvoxamine. Proc Natl Acad Sci U S A 95:3239-3244.

Vicini S, Wang JF, Li JH, Zhu WJ, Wang YH, Luo JH, Wolfe BB, Grayson DR (1998) Functional and pharmacological differences between recombinant $N$-methyl-D-aspartate receptors. J Neurophysiol 79:555-566.

Waxman EA, Lynch DR (2005) NMDA receptor subtypes: multiple roles in excitotoxicity and neurological disease. Neuroscientist 11:37-49.

Weaver CE Jr, Marek P, Park-Chung M, Tam SW, Farb DH (1997) Neuroprotective activity of a new class of steroidal inhibitors of the $\mathrm{N}$-methylD-aspartate receptor. Proc Natl Acad Sci U S A 94:10450-10454.

Wu FS, Gibbs TT, Farb DH (1991) Pregnenolone sulfate: a positive allosteric modulator at the $N$-methyl-D-aspartate receptor. Mol Pharmacol 40:333-336.

Yaghoubi N, Malayev A, Russek SJ, Gibbs TT, Farb DH (1998) Neurosteroid modulation of recombinant ionotropic glutamate receptors. Brain Res 803:153-160.

Zhang W, Howe JR, Popescu GK (2008) Distinct gating modes determine the biphasic relaxation of NMDA receptor currents. Nat Neurosci 11: 1373-1375. 